\title{
EVALUATION OF THE EFFECT OF EXTERNAL PRESTRESSED STEEL STRANDS ON CABLE-STAYED BRIDGES BASED ON FINITE ELEMENT ANALYSIS AND STATIC TEST
}

\author{
Chunwei Li, Haitao Yu, Dongzhe Jia and Quansheng Sun
}

\author{
Northeast Forestry University, Department of Civil Engineering, 26 Hexing road, \\ Harbin, PR China; Quansheng Sun;hrbsqs@126.com.
}

\begin{abstract}
This article relies on the reinforcement project of the Mulinghe cable-stayed bridge to explore the changes in the mechanical properties of the reinforced concrete cable-stayed bridge before and after reinforcement. The bridge has large cable spacing, large internal force of a single cable, and the main beam is mainly Reinforced Concrete. Therefore, structural calculation, disease analysis, and damage state simulation are carried out. Afterwards, the bridge's commonly used reinforcement methods were compared, and suitable reinforcement schemes were selected. After the reinforcement, the field test was carried out on the cable-stayed bridge, the main beam deflection, the strain of the main beam and the main tower, and the increase in the cable force of the cablestayed were analyzed. The results show that external prestressed reinforcement is the best way, which can significantly reduce the vertical displacement of the main beam and the horizontal displacement of the main tower, and also improve the stress on the upper and lower edges of the main beam. After the external prestressed reinforcement, the ratio of the observed value to the observed value in the filed load test of the cable-stayed bridge's decreased significantly. It is up to $31 \%$ increase in bending capacity of main beams and up to $24 \%$ increase in stiffness. This article is instructive for the reinforcement of the early-built sparse-cable reinforced concrete cable-stayed bridge, while also expanding the scope of implementation of external prestressed reinforcement technology.
\end{abstract}

\section{KEYWORDS}

External prestress, Cable-stayed bridge, Reinforcement, filed test

\section{INTRODUCTION}

The increase in traffic density and vehicle load are unavoidably damaged and aging, resulting in a considerable part of the in-service bridges with early construction time, especially cable-stayed bridges, can no longer meet the current safety and durability requirements. If these conditions are not controlled and strengthened, it will further seriously affect the safe use of the bridge. Therefore, considering the structural safety and economic benefits of the cable-stayed bridge, timely and effective maintenance and reinforcement work has become an important research topic in front of the majority of researchers.

Chen Hao [1] took a prestressed concrete cable-stayed bridge with a span of $(38.5+71+38.5)$ $\mathrm{m}$ as the research object, analyzed the damage of the superstructure of the cable-stayed bridge and established a finite element model, which was strengthened by section and adjusted by cable force. In the reinforcement method, the tension and compression stresses of the main beam and the tower are reduced, and the reinforcement effect is obvious. Pan Zhulan et al [2] conducted a cable 
replacement study for cable-stayed bridges based on disease detection. After the cable replacement of the full bridge was completed, a filed load test way was designed. The results show that the strength and rigidity of the bridge have been significantly improved. Lei Jinsheng et al [3] analyzed the cable force adjustment of 15 pairs of stay cables in the main technical steps. The study shows that the process of cable replacement and reinforcement has a great influence on the stress of the main beam of the bridge and the cable force of the linear and diagonal cables. After the reinforcement, the safety performance of the bridge structure meets the design requirements. Zou Zexi [4] used cross-section reinforcement and cable force adjustment to strengthen a PC cablestayed bridge. Through the finite element simulation of the cable-stayed bridge damage and reinforcement construction phase, the main girder alignment reached the expected goal after reinforcement and maintenance, and the cable force tended to be more uniform. J. Guo [5] applied the simulated annealing algorithm and the B-spline curve interpolation method to the cable force optimization of a three-span curved cable-stayed bridge. The cable force after the cable force adjustment was further optimized, and through the filed load test the effectiveness of this method is verified. Wu Zhongxin [6] used the comparison and mutual verification of the two finite element calculation software for the Tianjin Yonghe Bridge cable replacement project to monitor the parameters of the main beam linear and cable force during the cable replacement process and change the cable. The influence matrix method is used to optimize the cable force after cable replacement so that the reinforced cable-stayed bridge can reach the original design state. Qiao Changjiang [7] proposed the reinforcement way of the main beams with carbon fiber cloth and steel plates and replacement of stay cables based on the disease inspection, and focused on the cable replacement technology of the cable-stayed bridge. The geometry of the bridge changed slightly after changing the cable, and the stress state of the tower-beam consolidation is improved.

At present, domestic and foreign researchers on the reinforcement of cable-stayed bridges mainly focuses on the replacement of cable-stayed cables and the adjustment of cable strength. However, for the cable-stayed bridges built early in China, due to the large spacing of the cables, the large internal force of the single cable, and the main beam being mainly bent, In the general cable adjustment and cable replacement way, a backup cable must be set to prevent the stress of the main beam from exceeding the limit during the cable replacement process and causing cracks. During the reinforcement process, the stress on the main tower of the original bridge must be strictly monitored and strengthened, and the local compressive stress in the rear main beam span has not increased significantly. In the face of the general cable adjustment and cable replacement method, the construction process is complicated and the reinforcement effect is not good, it is more necessary to find a reinforcement method with good reinforcement effect and convenient construction without cable replacement. In this paper, taking a cable-stayed bridge in China as the research background, analysed of the bearing capacity of the cable-stayed bridge before and after reinforcement, and the filed load test is carried out to evaluated the bearing capacity of the cable-stayed bridge. This paper provides technical data for the subsequent operation, detection and maintenance of this bridge, provides references for the same type of construction methods, and improves the bridge reinforcement theory.

\section{BACKGROUND}

The cable-stayed bridge studied in this paper is a reinforced concrete T-beam cable-stayed bridge across Muling River in the eastern part of Heilongjiang Province. The bridge structure is a tower-pier consolidation and tower-beam separation system. The twin towers are 14 meters high, the bridge has a total length of $106.4 \mathrm{~m}$, the span combination is $28 \mathrm{~m}+50.4 \mathrm{~m}+28 \mathrm{~m}$, and the full bridge width is $9 \mathrm{~m}$. The upper structure is reinforced concrete T beam, each bridge tower is provided with 4 pairs of stay cables, and 16 pairs of stay cables are arranged on the upstream and downstream sides, and the anchor spacing on the main beam is $5.6 \mathrm{~m}$. The lower structure is a 
gravity bridge abutment, and the tower foundation uses a caisson foundation. The bridge panoramic photo is shown in Figure 1. The bridge was completed in October 1995, with a design load rating of car-20 and trailer-100.

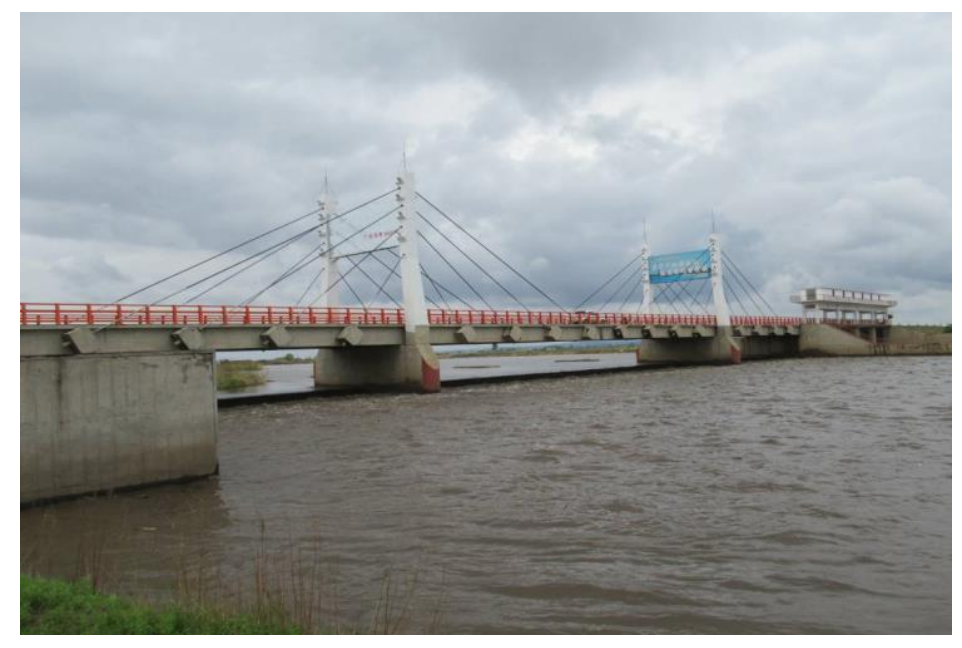

Fig. 1 - Elevation drawing of the cable-stayed bridge

During the 25 years of operation, there are multiple vertical cracks in the main beam web of each hole due to environmental effects and increasing vehicle load. The width of the crack is between $0.13 \sim 0.5 \mathrm{~mm}$, which exceeds the specified limit, there are more cracks in the mid-span area, and the main beam is severely deflected; The top and bottom beams have long longitudinal cracks, and the crack width is between $0.1 \sim 0.4 \mathrm{~mm}$, which exceeds the specified limit, and the cracks are irregularly distributed; The protective tube at the anchor end of the stay cables were damaged and the anchors were corroded. The apparent typical diseases are shown in Figure 2. Based on pathogen analysis, the reinforcement way proposed in this article.

$\mathrm{T}$ beam reinforcement: one longitudinal external prestressed beam is set on each side of each $\mathrm{T}$ beam, the steel beam is made of three high-strength low-relaxation steel strands of $\Phi 15.24$ $\mathrm{mm}$, the standard strength is $\mathrm{f}_{\mathrm{pk}}=1860 \mathrm{MPa}$, and the elastic modulus is $E_{p}=1.95 \times 10^{5} \mathrm{MPa}$, the tensile control force of a single steel strand is $168.05 \mathrm{kN}$, and the tensile control stress of the prestressed steel strand is $1209 \mathrm{MPa}$. The external prestressed steel beams are tensioned at both ends, using OVM15-3 anchors, which are respectively bent and anchored at the corresponding webs at both ends of the $T$ beam.

Cross beam reinforcement: the cross beam between the side beam and the middle beam is pasted with $\mathrm{N} 1$ steel plate with a size of $1500 \times 300 \times 10 \mathrm{~mm}$, the beams between the middle beams are pasted with N2 steel plates and the size is $2400 \times 300 \times 10 \mathrm{~mm}$ to strengthen the shear strength and suppress the crack development. The size of the N3 steel plate pasted at the bottom of each beam is $8400 \times 400 \times 10 \mathrm{~mm}$ in order to increase the bending resistance of the bottom plate. N1 and N2 steel plates are fixed with 10.9 grade $\varphi 22$ high strength bolts, and N3 steel plates are fixed with M12 high strength bolts. In order to ensure the bonding quality, the steel plate should also be scrubbed with gasoline to completely remove floating dust and oil stains, and then the steel plate should be pasted with an adhesive and fixed with high-strength bolts. Finally, in order to prevent the corrosion of the steel plate and delay the aging of the adhesive, the surface of the pasted steel plate should be sealed, waterproofed and rust-proofed after removing the surface oil stains and rust. The main beam and cross beam reinforcement are shown in Figure 3. 


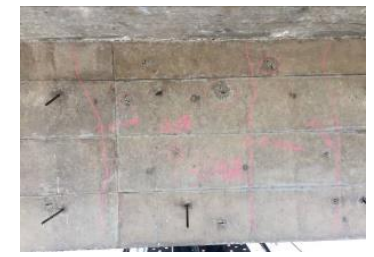

Vertical cracks in main span

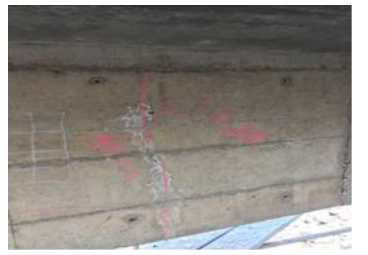

Vertical cracks in side span

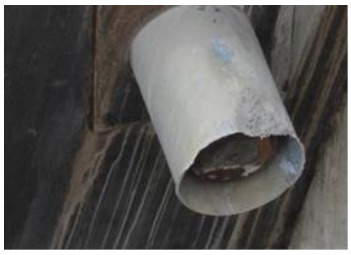

Broken protective tube

Fig. 2 - Apparent disease of cable-stayed bridge

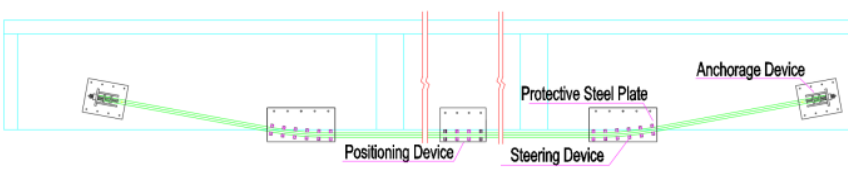

(a) External prestress layout of main beam

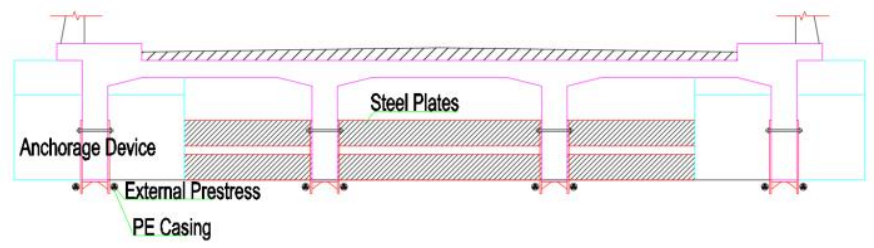

(c) Paste drawing of cross beam steel plate

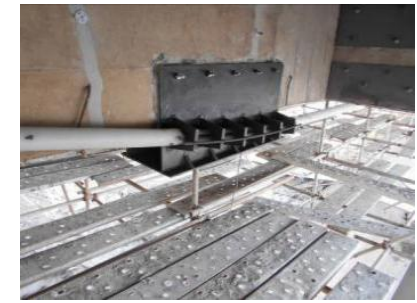

(b) Photo of external beam reinforcement of main beam

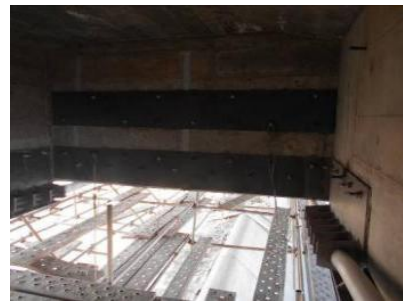

(d) Photo of steel plate pasted to cross beam

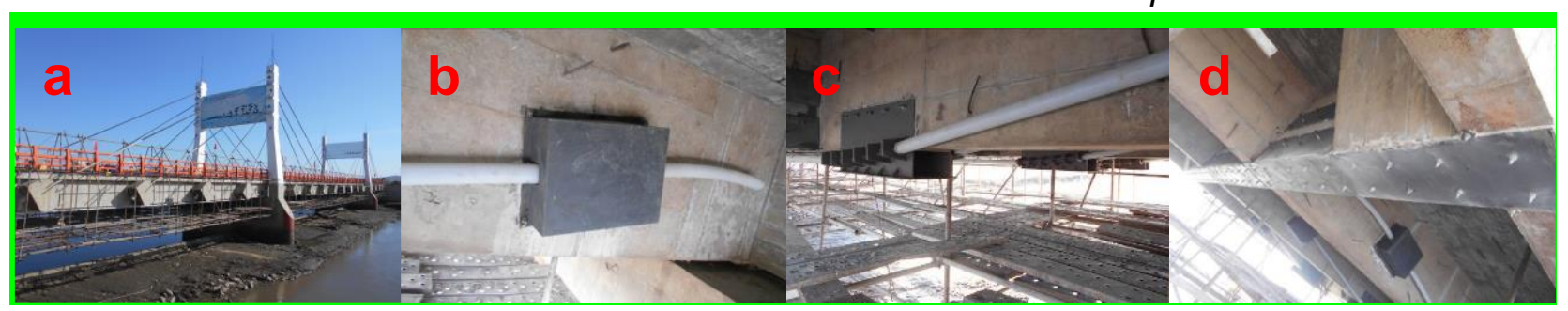

(e) Photo of the strengthened structure

Fig. 3 - Reinforcement drawing of main beam and cross beam

\section{METHODS}

\section{Comparison of reinforcement design schemes based on finite element analysis}

A total of five reinforcement ways, including external prestress reinforcement of the main girder by changing the parameter values and optimization and adjustment of the cable tension of the stay cables are proposed according to the analysis of the bridge disease on site. The reinforcement ways are shown in Table. 1. MIDAS / CIVIL was used to establish a finite element model considering disease damage simulation and theoretical calculation of five reinforcement ways. The model 
building process is divided into damage simulation stage and structural reinforcement simulation stage. Both the main beam and the main tower are simulated using plane beam elements, and the setting of the cross-sectional dimensions is consistent with the actual situation. Each cable adopts a truss unit with only a tensile structure and is divided into one unit. The whole bridge finite element model of the cable-stayed bridge includes 607 main beam elements and 128 main tower elements, and there are 32 tension-only truss (cable-stayed cable) units with a total of 800 nodes.

Damage simulation (the stiffness of the main beam section is reduced by $20 \%$, the shrinkage and creep coefficient is changed by $50 \%$, the environmental humidity is simulated, the cable tension is reduced by $3 \%$, and the cable damage is simulated) and reinforcement simulation (external restraint of main beam, steel plate pasted on beam, cable adjustment of stay cables) is carried out in the finite element model. Reinforcement simulation is to simulate the external beam of the main beam, the steel plate pasted to the beam, and the cable adjustment of the stay cable. The external beam is simulated by using the steel beam type as "external" and the friction coefficient and deviation coefficient of the pipeline are " 0 ", the steel plate reinforcement is simulated by the method of converting the elastic modulus of the beam, the aim is to find the most reasonable line shape and internal force state of the cable-stayed bridge for cable force optimization. The model of the cablestayed bridge after reinforcement is shown in Figure 4.

Tab. 1- Reinforcement way based on disease analysis

\begin{tabular}{|c|c|c|}
\hline $\begin{array}{l}\text { Type of } \\
\text { reinforcement }\end{array}$ & Way number & Reinforcement way \\
\hline \multirow{4}{*}{$\begin{array}{l}\text { External } \\
\text { prestress }\end{array}$} & Way1 & $\begin{array}{l}\text { Both sides of the main beam are reinforced with a bundle of } \\
\Phi 15.24 \mathrm{~mm} \text { prestressed steel beams, the tensile control stress is } \\
651 \mathrm{MPa} \text {, which is } 35 \% \text { of the standard strength. Maintenance of } \\
\text { the cable stay at the anchor end of the stay cable and the rust } \\
\text { removal of the anchor. }\end{array}$ \\
\hline & Way2 & $\begin{array}{l}\text { Both sides of the main beam are reinforced with a bundle of } \\
\Phi 15.24 \mathrm{~mm} \text { prestressed steel beams, the tensile control stress is } \\
930 \mathrm{MPa} \text {, which is } 50 \% \text { of the standard strength. Maintenance of } \\
\text { the cable stay at the anchor end of the stay cable and the rust } \\
\text { removal of the anchor. }\end{array}$ \\
\hline & & $\begin{array}{l}\text { Both sides of the main beam are reinforced with a bundle of } \\
\Phi 15.24 \mathrm{~mm} \text { prestressed steel beams, the tensile control stress is }\end{array}$ \\
\hline & Way3 & $\begin{array}{l}1209 \mathrm{MPa} \text {, which is } 65 \% \text { of the standard strength. Maintenance } \\
\text { of the cable stay at the anchor end of the stay cable and the rust } \\
\text { removal of the anchor. }\end{array}$ \\
\hline cable force & Way4 & Change the stay cable from long to short. \\
\hline optimization & Way5 & Change the stay cable from short to long. \\
\hline
\end{tabular}

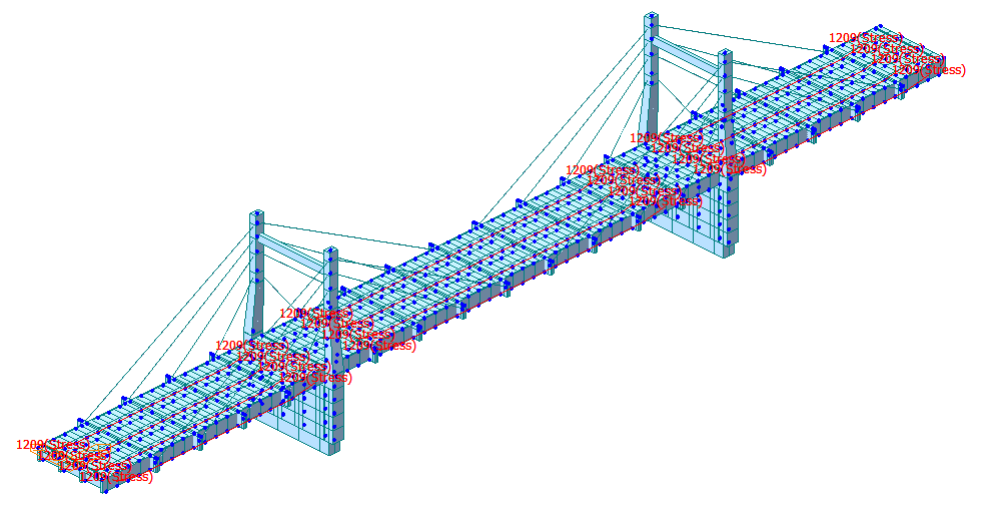


Fig. 4 - Finite element model of reinforced cable-stayed bridge

\section{Static test to verify the actual reinforcement effect}

The cable-stayed bridge sets 3 test sections according to the calculation results of the model: A-A section, B-B section, and C-C section. In order to prevent the damage caused by excessive transient load applied during the static behavior test of the cable-stayed bridge, and at the same time, it can intuitively and deeply understand the change trend of the main beam and cable-stayed structure of the cable-stayed bridge with the load, this static filed load test adopts 2-level loading mode, and the test cross-section is shown in Figure 5. The test content is shown in Table 2.

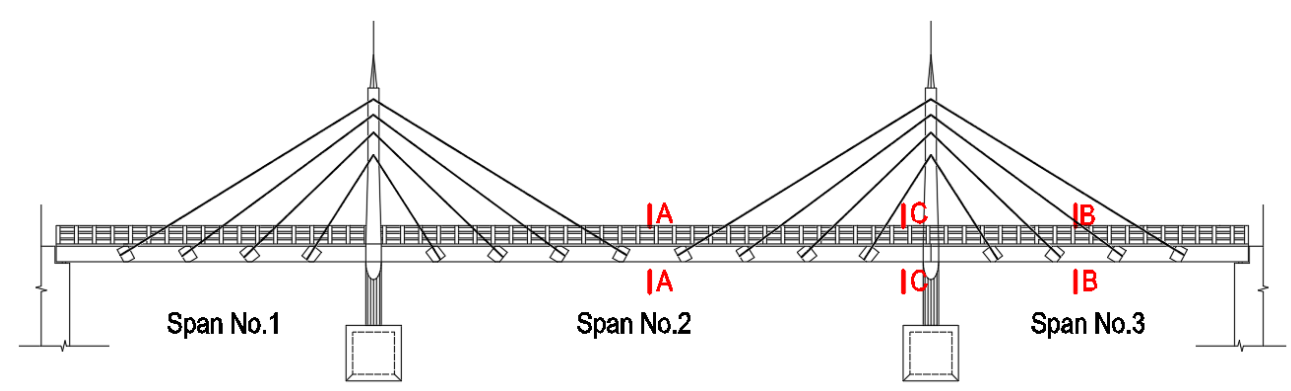

Fig. 5 - Schematic diagram of test section

Tab. 2 -Test items of each section

\begin{tabular}{|c|c|c|c|}
\hline $\begin{array}{l}\text { Static load } \\
\text { conditions }\end{array}$ & $\begin{array}{c}\text { Test } \\
\text { section }\end{array}$ & Test items & Test contents \\
\hline 1 & $A-A$ & $\begin{array}{l}\text { Maximum positive bending moment } \\
\text { of the (2\#spans) }\end{array}$ & $\begin{array}{l}\text { Deflection, strain, tower deflection, } \\
\text { cable force increment }\end{array}$ \\
\hline 2 & C-C & $\begin{array}{c}\text { Maximum negative bending } \\
\text { moment of the } 2 \# \text { Pier top section }\end{array}$ & Strain \\
\hline 3 & $B-B$ & $\begin{array}{l}\text { Maximum positive bending moment } \\
\text { of the side span ( } 3 \# \text { spans) }\end{array}$ & $\begin{array}{l}\text { Deflection, strain, tower deflection, } \\
\text { cable force increment }\end{array}$ \\
\hline
\end{tabular}


Measuring point arrangement: The vertical displacement measuring points of 2\# span and $3 \#$ span are arranged at the bottom section of the mid-span beam, the strain measuring points of $2 \#$ span and $3 \#$ are arranged at the mid-span section, and the negative bending moment measuring points of the 2\# pier fulcrum point, the cross section of the main beam on the right is evenly arranged, the strain measurement points of the cable tower are arranged at the root section of the $2 \#$ cable tower, and the offset measurement points of the cable tower are arranged at the top section of the tower, the arrangement of measuring points is shown in Figure 6.

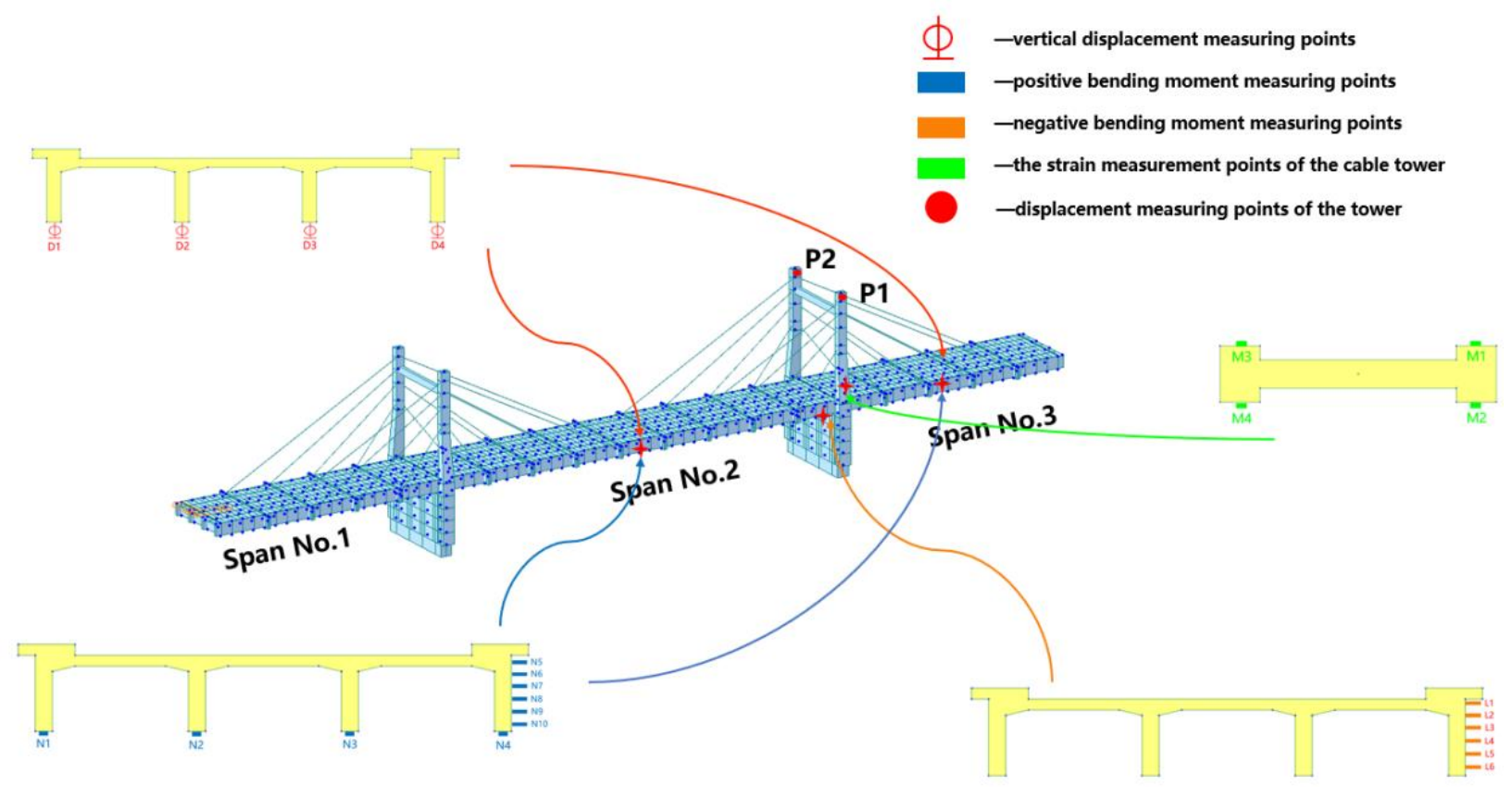

Fig. 6 - Layout of measuring points

In this static filed load test, four $300 \mathrm{kN}$ three-axle trucks were selected, the test loads before reinforcement were $303.6 \mathrm{kN}, 306.0 \mathrm{kN}, 300.2 \mathrm{kN}$, and $302.8 \mathrm{kN}$, and the test loads after reinforcement were $301.8 \mathrm{kN}, 302.4 \mathrm{kN}, 301.2 \mathrm{kN}$, and $303.8 \mathrm{kN}$. The on-site loading situation is shown in Figure 7. Table 3 shows the static filed load test efficiency.
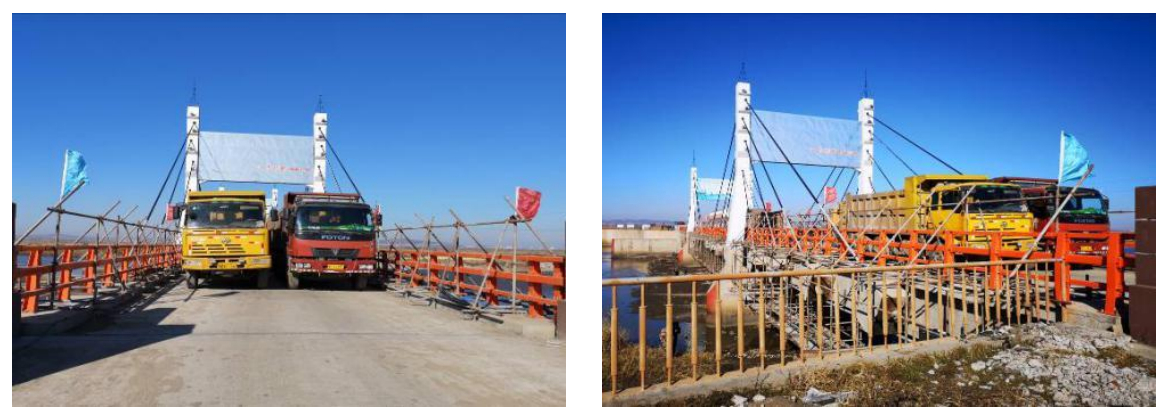

Fig. 7 - On-site loading situation 
Tab. 3 - static filed load test efficiency

\begin{tabular}{ccccc}
\hline $\begin{array}{c}\text { Static load } \\
\text { conditions }\end{array}$ & Test items & $\begin{array}{c}\text { Design bending } \\
\text { moment }(\mathrm{kN} \mathrm{m})\end{array}$ & $\begin{array}{c}\text { Loading bending } \\
\text { moment }(\mathrm{kN} \mathrm{m})\end{array}$ & $\begin{array}{c}\text { static filed load test } \\
\text { efficiency }\end{array}$ \\
\hline 1 & $\begin{array}{c}\text { A-A section } \\
\text { Partial load }\end{array}$ & 3246.1 & 3278.6 & 1.01 \\
2 & $\begin{array}{l}\text { B-B section } \\
\text { Partial load }\end{array}$ & -2214.8 & -2259.1 & 1.02 \\
3 & $\begin{array}{l}\text { C-C section } \\
\text { Partial load }\end{array}$ & 3096.7 & 3003.8 & 0.97 \\
\hline
\end{tabular}

\section{RESULTS}

\section{Reinforcement effect based on finite element analysis}

Aiming at the above five kinds of reinforcement schemes, theoretical analysis, data comparison and scheme comparison are carried out under the basic load combination specified in the document "Code for Design of Highway Reinforced Concrete and Prestressed Concrete Bridges and Culverts". In consideration of the displacement of the main beam, the main tower deflection, the cable force of the stay cable, the stress on the upper and lower edges of the main beam, and finally determine two different types of reinforcement schemes represented by Way 3 and Way 4, the changes of the stress characteristics of the bridge before and after the two ways are strengthened are shown in Figure 8.

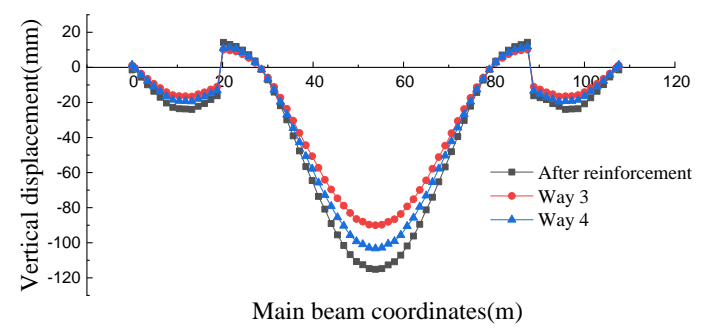

(a) Vertical displacement comparison of main beam

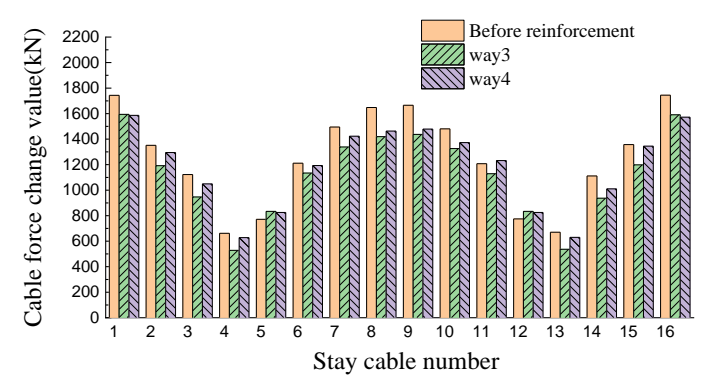

(c) Cable force comparison of stay cable

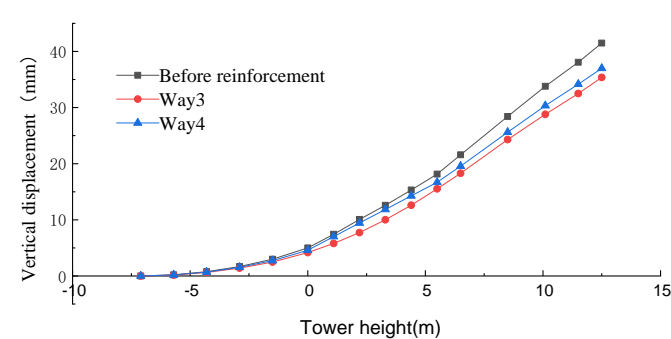

(b) Horizontal displacement comparison of main tower

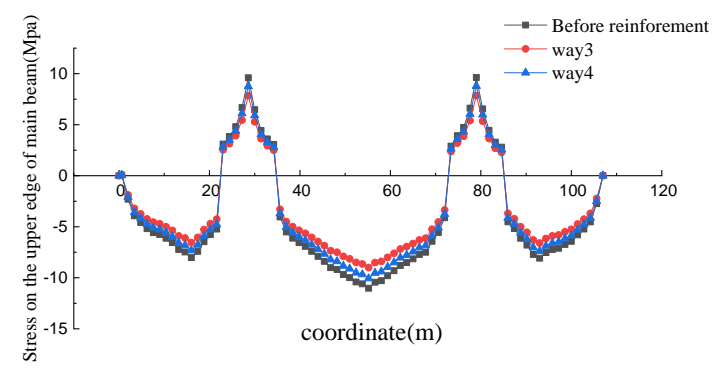

(d) Comparison of stress on the upper edge of main beam 


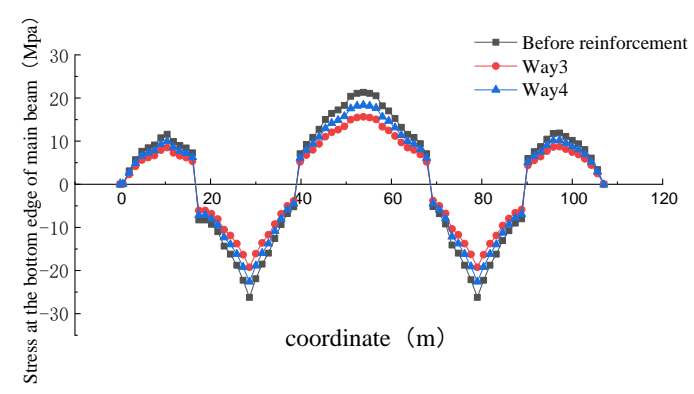

(e) Stress comparison of the lower edge of the main beam

Fig. 8 - Comparison of reinforcement effects of two ways

The above two reinforcement schemes will reduce the vertical displacement of the main beam of the cable-stayed bridge, the horizontal displacement of the main tower and cable force of the cable stay, and the stress on the upper and lower edges of the main beam. In the deflection analysis, the reinforcement effect of Way 3 is more significant, after reinforcement, the maximum vertical displacement of the mid-span main beam is reduced by $11.49 \%$ compared with Way 4 , and the maximum vertical displacement of the side-span main beam is reduced by $11.89 \%$. The effect of Way 3 on the deflection of the main tower is more significant, after the reinforcement of Way 3 , the maximum horizontal displacement of the main tower is reduced by $3.89 \%$ compared with Way 4. In the cable force analysis, the reinforcement effect of Way 3 and Way 4 is close, after reinforcement, the cable force values of $2 \# \sim 4 \#, 6 \# \sim 11 \#, 13 \# \sim 15 \#$ in the cable stay are lower than those in Way 4, 1\# ,5\#, 12\#, 16\# cable stay cable strength value has been improved compared with the Way 4. In the stress analysis, the reinforcement effect of Way 3 is more significant, after the reinforcement of Way 3, the maximum stress of the upper edge of the mid-span main beam is reduced by $9.7 \%$ more than that of Way 4 , and the maximum stress of the upper edge of the side span main beam is reduced by $9.71 \%$, the maximum stress of the lower edge of the beam is reduced by $12.8 \%$ more than that of Way 4 , and the maximum stress of the lower edge of the main beam of the side span is reduced by $12.83 \%$.

In summary, the final reinforcement way adopted for the cable-stayed bridge is Way 3 , which can significantly reduce the vertical displacement of the main beam and the horizontal displacement of the main tower. It also has an improvement effect on the stress of the upper and lower edges of the main beam and can meet the highway-II vehicle load Usage requirements.

\section{Reinforcement effect static on load test analysis}

\section{Analysis of the vertical displacement of the main beam before and after reinforcement}

The vertical displacement of the structure is a parameter that can reflect the structural stiffness macroscopically and is an important control index of the static test. This main beam vertical displacement measurement uses a dial indicator and a magnetic table base for detection. Table 4 is the comparison of vertical displacement before and after reinforcement of $2 \#$ span and $3 \#$ span under partial load. 
Tab. 4 - Comparison of vertical displacement before and after reinforcement

\begin{tabular}{|c|c|c|c|c|c|c|c|c|c|c|c|}
\hline \multirow[b]{2}{*}{ conditions } & \multirow[b]{2}{*}{$\begin{array}{c}\text { point } \\
\text { number }\end{array}$} & \multicolumn{4}{|c|}{ Test value before reinforcement } & \multicolumn{4}{|c|}{ Test value after reinforcement } & \multicolumn{2}{|c|}{ Promotion } \\
\hline & & $\begin{array}{c}\text { Level } 1 \\
\text { loading } \\
\text { measure } \\
\text { d value }\end{array}$ & $\begin{array}{l}\text { Level } 2 \\
\text { loading } \\
\text { measure } \\
\text { d value } \\
\text { (a) }\end{array}$ & $\begin{array}{c}\text { Theoreti } \\
\text { cal value } \\
\text { (b) }\end{array}$ & $\begin{array}{c}\text { Measured } \\
\text { value/the } \\
\text { oretical } \\
\text { value (c) }\end{array}$ & $\begin{array}{l}\text { Level } 1 \\
\text { loading } \\
\text { measure } \\
\text { d value }\end{array}$ & $\begin{array}{l}\text { Level } 2 \\
\text { loading } \\
\text { measure } \\
\text { d value } \\
\text { (d) }\end{array}$ & $\begin{array}{l}\text { Theore } \\
\text { tical } \\
\text { value } \\
(\mathrm{e})\end{array}$ & $\begin{array}{c}\text { Measured } \\
\text { value/theo } \\
\text { retical } \\
\text { value }(f)\end{array}$ & $\begin{array}{c}\text { Bearing } \\
\text { capacity } \\
\text { Promotion } \\
(\text { e-d }) / e- \\
(b-a) / b\end{array}$ & $(c-f) / c$ \\
\hline \multirow{4}{*}{ I } & D1 & 22.64 & 39.09 & 32.79 & 1.19 & 13.99 & 24.48 & 27.83 & 0.88 & 0.31 & 0.26 \\
\hline & $\mathrm{D} 2$ & 25.46 & 43.78 & 36.05 & 1.21 & 15.56 & 27.96 & 31.57 & 0.89 & 0.33 & 0.27 \\
\hline & D3 & 28.26 & 48.46 & 42.45 & 1.14 & 16.66 & 30.12 & 34.47 & 0.87 & 0.27 & 0.23 \\
\hline & D4 & 30.26 & 51.79 & 45.02 & 1.15 & 18.19 & 32.14 & 37.28 & 0.86 & 0.29 & 0.25 \\
\hline & D1 & 8.06 & 16.48 & 14.81 & 1.11 & 4.06 & 10.13 & 11.19 & 0.91 & 0.21 & 0.19 \\
\hline & D2 & 9.36 & 19.52 & 16.89 & 1.16 & 5.29 & 12.51 & 13.65 & 0.92 & 0.24 & 0.21 \\
\hline & D3 & 10.39 & 21.82 & 18.63 & 1.17 & 6.48 & 14.19 & 15.12 & 0.94 & 0.23 & 0.20 \\
\hline & D4 & 11.27 & 23.06 & 19.97 & 1.15 & 6.93 & 15.40 & 16.49 & 0.93 & 0.22 & 0.19 \\
\hline
\end{tabular}

Under the condition 1 , the ratio of the measured value and the theoretical value of the vertical displacement loading at the measuring point is $0.86 \sim 0.89$, with an average of 0.875 ; Under the condition 3 , the ratio of the measured value of the vertical displacement of the measuring point to the theoretical value is $0.91 \sim 0.94$, with an average of 0.925 ;

After the reinforcement of the main beam under the load of each working condition, the measured vertical displacement values of each measurement point are less than the theoretical value, and the stiffness of the bridge after reinforcement is satisfied, and the ratio between the measured value and the theoretical value of the main span loading is increased by $27 \%$, and the bearing capacity is increased by $33 \%$. The ratio between the measured value of the side span and the theoretical value can be increased by up to $20 \%$, and the bearing capacity can be increased by up to $24 \%$. The results show that the external prestressed reinforcement method significantly reduces the vertical displacement of the main beam and effectively improves the load-bearing capacity and stiffness of the cable-stayed bridge.

\section{Analysis of strain of main beam before and after reinforcement}

Strain is also an important data that intuitively reflects the stress on the bridge. A comprehensive tester is connected to the pre-embedded concrete strain gauge to detect strain. The strain comparison of the main components before and after reinforcement is shown in Figures 9-11 


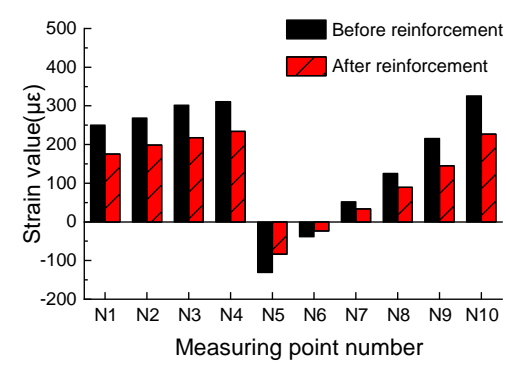

Strain comparison of 2\# span main beam before and after reinforcement $(\mu \varepsilon)$

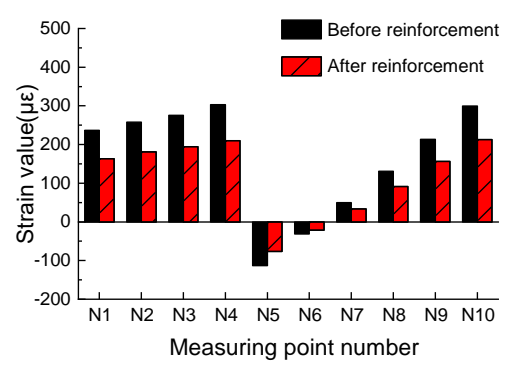

Strain comparison of $3 \#$ span main beam before and after reinforcement $(\mu \varepsilon)$

Fig. 9 - Comparison of the measured strain values before and after the reinforcement of the main beam

The ratio of the measured value and the theoretical value of the Level 2 loading of the main span strain measurement point is $0.85 \sim 0.96$, with an average of 0.91 ; The side span ratio is $0.84 \sim 0.92$, the average is 0.880 .

It can be seen from Figure 9 that after reinforcement, the measured strain value at each measuring point is less than the theoretical calculation value under each condition, the strength of the bridge after reinforcement is satisfied. After the main span is strengthened, the ratio between the measured value and the theoretical value is increased by up to $34 \%$, and the load capacity is increased by up to 28\%; After the reinforcement of the side span, the ratio between the measured value and the theoretical value is up to $26 \%$, and the bearing capacity is up to $31 \%$, indicating that the external prestressed reinforcement has a significant improvement effect on the stress level of the main beam.

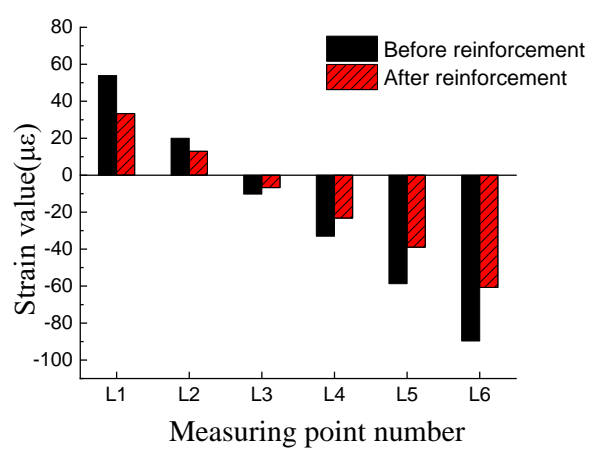

Fig. 10 - Comparison of strain of partial load on the top of 2\# pier before and after reinforcement

The ratio of the measured and theoretical values of the strain on the top of the pier under the test load is $0.41 \sim 0.54$, with an average of 0.475 ; It can be seen from Figure 10 that the measured strain value is less than the theoretical value under the load of each condition after reinforcement, and the strength of the bridge after reinforcement meets the design requirements. After reinforcement, the ratio between the measured value and the theoretical value of the 2 level loading is up to $32 \%$, and the load capacity is up to $25 \%$, indicating that the external prestressed reinforcement significantly increased the stress of the main beam. 


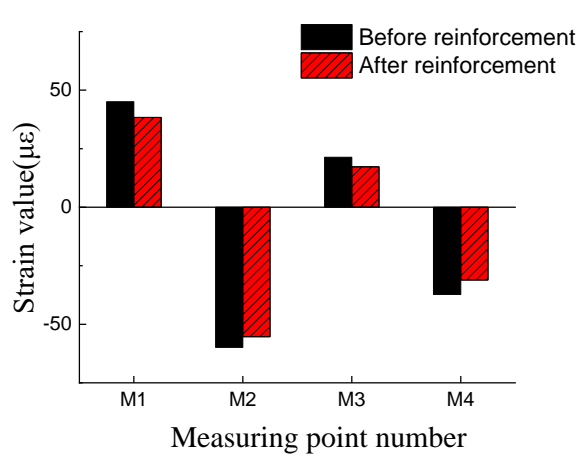

Comparison of measured strain of cable tower before and after reinforcement of $2 \#$ spans

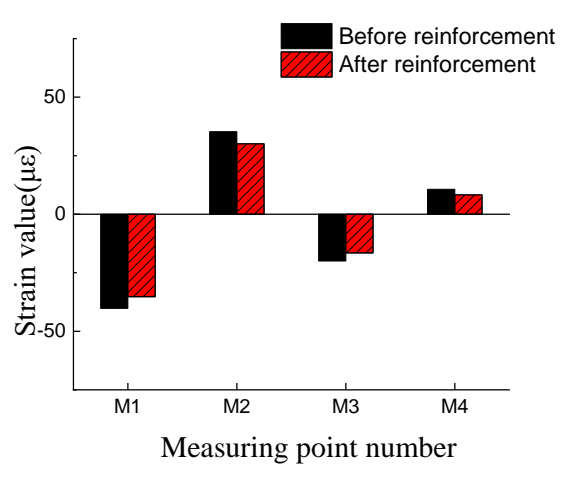

Comparison of measured strain of cable tower before and after reinforcement of $3 \#$ spans

Fig. 11 - Comparison of measured strains of cable tower before and after reinforcement

The ratio of the measured and theoretical values of the cable tower strain under level 1 loading is $0.41 \sim 0.54$, with an average of 0.475 ; The ratio of the measured and theoretical values of the strain under level 3 loading is $0.69 \sim 0.77$, with an average of 0.73 .

After reinforcement, the ratio between the measured value and the theoretical value of the level 2 loading is up to $10 \%$, and the load capacity is up to $8 \%$, indicating that the external prestressed reinforcement significantly increased the stress of the cable tower.

\section{Offset analysis of main tower before and after reinforcement}

Set a measuring point on the top and bottom of the D-D section of the top of the tower, and use a prism-free total station to test the deflection of the top of the tower after the static conditions are fully loaded and stable. Table 5 shows the detection offset results of the main tower, the positive values in the table represent the northwest direction, and the negative values represent the southeast direction.

Tab. 5- Comparison of measured offset of main tower before and after reinforcement $(\mathrm{mm})$

\begin{tabular}{|c|c|c|c|c|c|c|c|c|c|c|c|}
\hline \multirow[b]{2}{*}{ conditions } & \multirow[b]{2}{*}{$\begin{array}{c}\text { point } \\
\text { number }\end{array}$} & \multicolumn{4}{|c|}{ Test value before reinforcement } & \multicolumn{4}{|c|}{ Test value after reinforcement } & \multicolumn{2}{|c|}{ Promotion } \\
\hline & & $\begin{array}{l}\text { Level } 1 \\
\text { loading } \\
\text { measure } \\
\text { d value }\end{array}$ & $\begin{array}{l}\text { Level } 2 \\
\text { loading } \\
\text { measure } \\
\text { d value } \\
\text { (a) }\end{array}$ & $\begin{array}{l}\text { Theoreti } \\
\text { cal value } \\
\text { (b) }\end{array}$ & $\begin{array}{c}\text { Measured } \\
\text { value/the } \\
\text { oretical } \\
\text { value (c) }\end{array}$ & $\begin{array}{l}\text { Level } 1 \\
\text { loading } \\
\text { measure } \\
\text { d value }\end{array}$ & $\begin{array}{l}\text { Level } 2 \\
\text { loading } \\
\text { measure } \\
\text { d value } \\
\text { (d) }\end{array}$ & $\begin{array}{c}\text { Theore } \\
\text { tical } \\
\text { value } \\
(e)\end{array}$ & $\begin{array}{c}\text { Measured } \\
\text { value/theo } \\
\text { retical } \\
\text { value }(f)\end{array}$ & $\begin{array}{c}\text { Bearing } \\
\text { capacity } \\
\text { Promotion } \\
(e-d) / e- \\
(b-a) / b\end{array}$ & $(c-f) / c$ \\
\hline & $\mathrm{P} 1$ & 5.1 & 9.4 & 11.49 & 0.82 & 3.9 & 7.3 & 10.18 & 0.72 & 0.10 & 0.12 \\
\hline & $\mathrm{P} 2$ & 6.7 & 12.3 & 15.36 & 0.80 & 5.5 & 10.2 & 13.69 & 0.75 & 0.06 & 0.07 \\
\hline & P1 & -2.5 & -4.9 & -6.27 & 0.78 & -2.1 & -4.0 & -5.52 & 0.72 & 0.06 & 0.07 \\
\hline & P2 & -3.7 & -7.2 & -8.97 & 0.80 & -2.8 & -5.5 & -7.84 & 0.70 & 0.10 & 0.13 \\
\hline
\end{tabular}


Article no. 24

THE CIVIL ENGINEERING JOURNAL 1-2021 
It can be seen from Table 5 that under eccentric loading, the measured value of the main tower's deflection is smaller than the theoretical value, and the main tower's deflection trend is consistent. After reinforcement, the ratio between the measured value and the theoretical value is increased by $13 \%$, and the load capacity is increased by up to $10 \%$, indicating that the stiffness of the main tower of the cable-stayed bridge after reinforcement is qualified.

\section{Incremental analysis of cable force before and after reinforcement}

The cable force test is carried out using a cable force tester, the measured and calculated cable force increment of the typical cable near the test cross-section are shown in Figure 12.

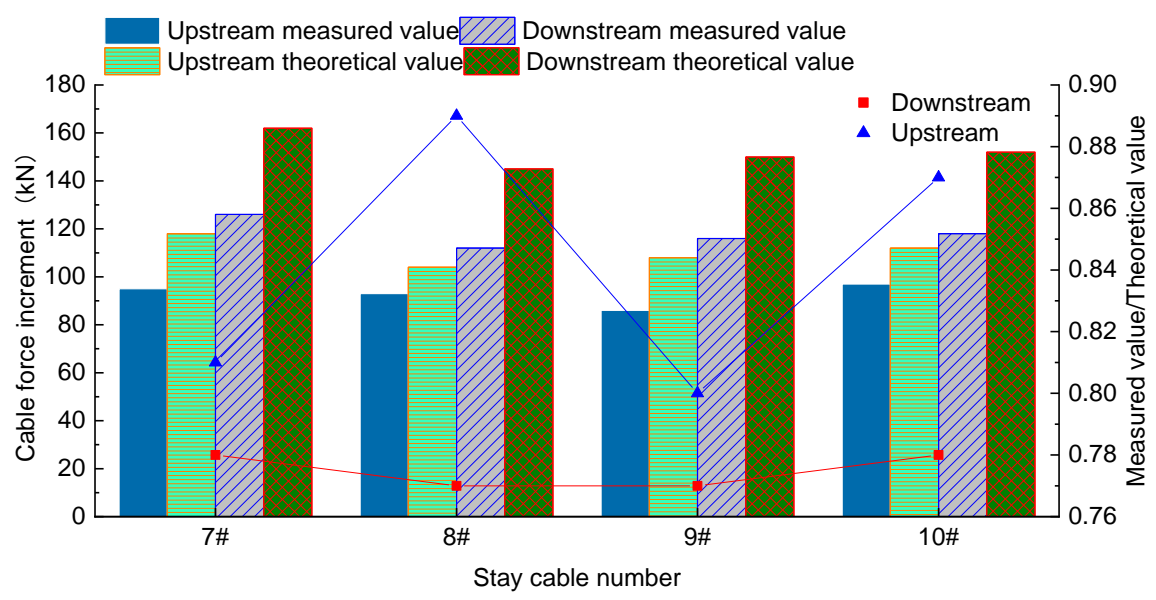

Condition1: Change of cable force before and after reinforcement

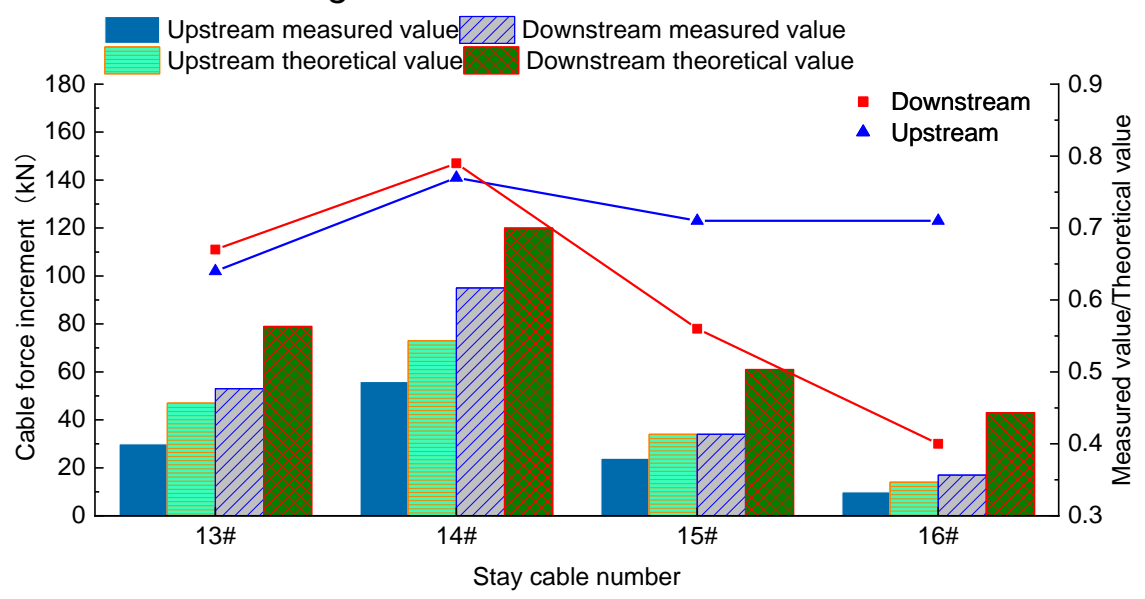

Condition3: Change of cable force before and after reinforcement

Fig. 12 - Change of cable force before and after reinforcement

The ratio of the measured and calculated values of each typical cable force of the cablestayed bridge is 0.40 to 0.89 , and the trend of the measured cable force and the calculated cable force is generally consistent. But the ratio of the measured value to the calculated value of the stay cable is generally low. The analysis shows that the stay cable is a parallel steel wire with a sheath outside the cable. At the same time, the sag effect of the stay cable has an influence on the determination of the cable force value.

The cable force increases of the cable stay on the upstream side of the cable-stayed bridge is significantly smaller than the cable force increases of the cable stay on the downstream side. The 
asymmetry amplitude of the cable force increment ranges from $17 \%$ to $43 \%$, maximum asymmetry amplitude is in condition 3.

\section{CONCLUSION}

(1) External prestressed reinforcement technology can greatly increase the bending capacity of the main beam, reduce the main tensile stress, and increase the safety reserve of compressive stress.

(2) The maximum vertical displacement of the main beam of Way 3 is $11.49 \%$ 11.89\% lower than that of Way 4; the maximum horizontal displacement of the main tower of Way 3 is $3.89 \%$ lower than that of Way 4; the maximum stress of the upper edge of the main beam of Way 3 is lower than that of the Way 4 decreased by $9.70 \%$ to $9.71 \%$; the maximum stress of the lower edge of the main beam of Way 3 was reduced by $12.80 \%$ to $12.83 \%$ more than Way 4 ; the reinforcement effect of Way 3 and Way 4 in the cable force analysis was close. The final reinforcement way adopted for the cable-stayed bridge is Way 3 , which can significantly reduce the vertical displacement of the main beam and the horizontal displacement of the main tower, and also improve the stress on the upper and lower edges of the main beam.

(3) Based on the comparison of the static filed load test data of the actual bridge before and after the reinforcement of the cable-stayed bridge, the measured strain and displacement of the main beam main tower are less than the calculated value after the reinforcement, and the change trend of the measured cable force is consistent with the calculated cable force. The application of external prestressed reinforcement technology to the cable-stayed bridge can significantly improve the strength, stiffness and safety reserve of the structure, and the bearing capacity of the bridge has improved significantly.

\section{REFERENCES}

[1] Chen hao,2015.Calculation and analysis of prestressed concrete cable-stayed bridge and its reinforcement scheme.Southwest Jiaotong University.

[2] Pan Zhulan,Zhao Changjun,Lou liang,2011. Design and Construction of Cable Replacement of Zhangzhen Cable-stayed Bridge.Highway, vol. $08: 89-92$.

[3] Lei Jinsheng,Wang Yongfei,Dai Xiaodong,2010. Maintenance and reinforcement design of the main bridge of Changsha Yinpenling Xiangjiang River Bridge. Highway Engineering, vol. 35(04):97-99+115.

[4] Zhou Zexi,Chen Yunhai,2014. Analysis of the whole process control of cable-stayed bridge construction, maintenance and reinforcement. Journal of Highway and Transportation Research and Development, vol. 31(04):100-105.

[5] J. Guo, Wancheng Yun,2019.Cable force optimization of a curved cable-stayed bridge with combined simulated annealing method and cubic B-Spline interpolation curves. Engineering Structures, vol.201:109813.

[6] Wu Zhongxin,Sheng Haijun,2013. Construction monitoring technology for reinforcement and reconstruction of cable-stayed bridge. Highway, vol.01:100-103.

[7] Qiao Changjiang,2010. Research on Cable Replacement Technology of Prestressed Concrete Cable-stayed Bridge. Huazhong University of Science and Technology.

[8] Liu Huichao, 2015. Research on Strengthening Technology of Prestressed Concrete Continuous Beam Bridge. Chang'an University.

[9] Jia Libo, 2012. Analysis of Active Reinforcement Methods of Prestressed Concrete Monolithic Box Girder Bridges with Small and Medium Spans. Chang'an University.

[10] Song Guangjun,Hua Longhai,2014. Analysis of Cracks in Diaphragm of Steel Box Girder of a Cablestayed Bridge and Research on Reinforcement.Bridge Construction, vol. 44(04):107-111.

[11] Niu Bin,1999. Analysis of Bending Performance of External Prestressed Concrete Beam. China Civil Engineering Journal, vol. 04:3-5 
[12] Liu Hang,Gao Huizong,Yang Xuezhong et al,2012. Post-tensioned external prestress reinforcement technology and its engineering application. Architecture Technology, vol. 43(01):49-52.

[13] Angel C. Aparicio, Gonzalo Ramos, Juan R. Casas,2002.Testing of externally prestressed concrete beams, Engineering Structures, vol.24:73-84.

[14] Ghallab A H, Khafaga M A, Farouk M F ,et al, 2013. Shear behavior of concrete beams externally prestressed with Parafil ropes. Ain Shams Engineering Journal, vol.4(01):1-16.

[15] Tiejiong,Loua,Sergio,M.R.Lopes,2012.Numerical analysis of behaviour of concrete beams with external FRP tendons.Construction and Building Materials, vol.35:970-978.

[16] Dong Bin, 2009. Experimental Study on Strengthening of Concrete Beams with External Prestress Considering the Influence of Secondary Axial Force. Tianjin University.

[17] Qu Dechao, 2013. Research on Strengthening of External Prestress of Reinforced Concrete Continuous Curved Beam Bridge. Harbin Institute of Technology.

[18] Lv Liang,Jia Yi,Ji Yuntao,2019. Evaluation of Bearing Capacity of Double-Tower Partial Cable-stayed Bridge Based on Load Test. Journal of Architecture and Civil Engineering, vol.36(03):101-109.

[19] Liu Yongjian, Yang Jian,Liang Peng et al,2009. Load test of cable-stayed bridge without backstay leaning tower. Journal of Chang'an University (Natural Science Edition), vol.29(05):59-63.

[20] Alemdar Bayratar,Temel Turker,et al,2017.Static and dynamic field load testing of the long span Nissibi cable-stayed bridge. Soil Dynamics and Earthquake Engineering, vol.94:136-157.

[21] Dall'Asta A, Ragni L, Zona A, 2007 . Simplified Method for Failure Analysis of Concrete Beams Prestressed with External Tendons. Journal of Structural Engineering, vol.133:121-131.

[22] Richard Andrew Barnes, Geoffrey Charles Mays,2006. Strengthening of reinforced concrete beams in shear by the use of externally bonded steel plates: Part 1- Experimental programme. Construction and building materials, vol.20: 396-402.

[23] Bimal Babu Adhikary, Hiroshi Mutsuyoshi,2006. Shear strengthening of RC beams with web-bonded continuous steel plates, Construction and Building Materials, vol.20:296-307.

[24] Zhang D, Ueda T, Furuuchi H, 2012. Concrete cover separation failure of overlay-strengthened reinforced concrete beams. Construction \& Building Materials, vol.26(01):735-745.

[25] Liu Chuanle,Zhang Guogang,2018. Static load test study on a super long-span suspension bridge spanning cable crane. Journal of China and Foreign Highway , vol.38(05):105-108.

[26] Liu Kai,Pei Bingzhi,Zhang Menzhe et al,2019. Research on Reasonable Distribution of Girder Section Rigidity and Bearing Capacity in the Region Around Steel-Concrete Joint Section of Hybrid Girder Cable-stayed Bridge. Journal of China and Foreign Highway, vol.39(06):66-72. 